\title{
Predictors of dyspnoea prevalence: results from the BOLD study
}

\author{
Rune Grønseth ${ }^{1,2}$, William M. Vollmer ${ }^{3}$, Jon A. Hardie ${ }^{1,2}$, Inga Sif Ólafsdóttir ${ }^{4}$, \\ Bernd Lamprecht ${ }^{5}$, A. Sonia Buist ${ }^{6}$, Louisa Gnatiuc ${ }^{7}$, Amund Gulsvik ${ }^{1,2}$, \\ Ane Johannessen ${ }^{8}$ and Paul Enright ${ }^{9}$
}

\begin{abstract}
Affiliations: 'Dept of Clinical Science, University of Bergen, Bergen, ${ }^{2}$ Dept of Thoracic Medicine, Haukeland University Hospital, Bergen, and ${ }^{8}$ Centre for Clinical Research, Haukeland University Hospital, Bergen, Norway. ${ }^{3}$ Kaiser Permanente Center for Health Research, Portland, OR, and ${ }^{6}$ Oregon Health and Sciences University, Portland, OR, USA. "Respiratory Medicine and Allergology, Dept of Medical Sciences, Uppsala University, University Hospital, Uppsala, Sweden. ${ }^{5}$ Dept of Pulmonary Medicine, Paracelsus Medical University, Salzburg, Austria. ${ }^{7}$ Respiratory Epidemiology and Public Health, Imperial College, London, UK. ${ }^{9}$ University of Arizona, Tucson, AZ, USA.
\end{abstract}

Correspondence: Rune Grønseth, Dept of Thoracic Medicine, Haukeland University Hospital, N-5021 Bergen, Norway. E-mail: nielsenrunedme.com

ABSTRACT Dyspnoea is a cardinal symptom for cardiorespiratory diseases. No study has assessed worldwide variation in dyspnoea prevalence or predictors of dyspnoea.

We used cross-sectional data from population-based samples in 15 countries of the Burden of Obstructive Lung Disease (BOLD) study to estimate prevalence of dyspnoea in the full sample, as well as in an a priori defined low-risk group (few risk factors or dyspnoea-associated diseases). Dyspnoea was defined by the modified Medical Research Council questions. We used ordered logistic regression analysis to study the association of dyspnoea with site, sex, age, education, smoking habits, low/high body mass index, selfreported disease and spirometry results.

Of the 9484 participants, $27 \%$ reported any dyspnoea. In the low-risk subsample ( $n=4329), 16 \%$ reported some dyspnoea. In multivariate analyses, all covariates were correlated to dyspnoea, but only $13 \%$ of dyspnoea variation was explained. Females reported more dyspnoea than males (odds ratio $\sim 2.1$ ). When forced vital capacity fell below $60 \%$ of predicted, dyspnoea was much more likely.

There was considerable geographical variation in dyspnoea, even when we adjusted for known risk factors and spirometry results. We were only able to explain $13 \%$ of dyspnoea variation.

@ERSpublications

Known predictors and risk factors can only explain $13 \%$ of dyspnoea variation http://ow.ly/tHSOH

For editorial comments see page 1547.

This article has supplementary material available from www.erj.ersjournals.com

Received: Feb 272013 | Accepted after revision: Oct 122013 | First published online: Oct 312013

Support statement: The initial BOLD programme was funded in part by unrestricted educational grants to the Operations Center in Portland, OR, USA, from ALTANA, Aventis, AstraZeneca, Boehringer-Ingelheim, Chiesi, GlaxoSmithKline, Merck, Novartis, Pfizer, Schering-Plough, Sepracor, and the University of Kentucky. Since 2008, the BOLD Study has been funded by a grant from the Wellcome Trust $(085790 / \mathrm{Z} / 08 / \mathrm{Z})$. Additional local support for BOLD sites was provided by those listed in the Acknowledgements section.

Conflict of interest: Disclosures can be found alongside the online version of this article at www.erj.ersjournals.com

Copyright @ERS 2014 


\section{Introduction}

The presence of dyspnoea predicts long-term mortality [1] and characterises high-prevalence diseases, such as congestive heart failure, ischaemic heart disease, chronic obstructive pulmonary disease (COPD) and asthma. In 2004, ischaemic heart disease, lower respiratory infections and COPD together accounted for $>14$ million deaths worldwide [2]. In COPD, chronic dyspnoea is one of the strongest predictors of poor quality of life [3], an important predictor of exacerbation outcomes [4], and a marker of both disease severity and disability.

Dyspnoea prevalence has varied greatly across studies [5-9] and countries [10, 11]. Some might be due to differences in the distribution of known correlates of dyspnoea, such as age, sex and smoking status $[6,8,9,11,12]$. However, differences might also reflect variation in how dyspnoea was measured, the nature of the samples studied and the burden of chronic diseases that cause dyspnoea. Various dyspnoea scales have been proposed, but no consensus exists regarding which scale to choose and whether the standard approach of picking a rather arbitrary cut-off for defining dyspnoea is appropriate. By reducing dyspnoea to a graded scale, some information is inevitably lost.

Some population-based studies have reported a dyspnoea prevalence of $>20 \%[6,7,11,13]$. A high prevalence of cardiopulmonary diseases, lifestyle changes, obesity and subclinical medical conditions might have explained this dyspnoea. To improve understanding of geographical variation in dyspnoea and its correlates, large international studies using standardised methods are needed. The PLATINO study was a population-based study in São Paulo (Brazil), Santiago (Chile), Mexico City (Mexico), Montevideo (Uruguay) and Caracas (Venezuela) [14]. They reported several correlates of dyspnoea, including sex, forced expiratory volume in $1 \mathrm{~s}$ (FEV1) \% predicted, comorbidities, age, body mass index (BMI), race, education, quality of life and other respiratory symptoms that all predicted (any) dyspnoea [11]. Dyspnoea was defined by a dichotomous cut-off using standardised questionnaires in Spanish and Portuguese in Latin American countries.

As in the PLATINO study, the Burden of Obstructive Lung Diseases (BOLD) study was also designed to estimate the social and economic burden of COPD. In order to provide state-of-the-art estimates, population-based samples from American, European, Asian, African and Oceanic countries were recruited and investigated using standardised questionnaires and post-bronchodilation spirometry [15]. Dyspnoea was evaluated by the five-level modified Medical Research (mMRC) questionnaire [16], measuring the impact domain of activity-related dyspnoea. The BOLD study applied identical methods across culturally and geographically diverse study sites and, thus, provided a unique opportunity to assess correlates of dyspnoea.

Our goal in this article was to examine the prevalence and correlates of self-reported dyspnoea across sites representing substantial geographical variation. Using BOLD data from 15 countries and strictly standardised methods, we examined a variety of possible predictors. By using ordered logistic regression we were able to avoid dichotomising a multilevel categorical variable. In addition, we estimated the degree of dyspnoea reporting in low-risk individuals by examining how dyspnoea prevalence changed when subjects with risk factors for dyspnoea, spirometric lung function impairment and self-reported dyspnoeacausing conditions were excluded.

\section{Methods \\ Study population}

The design of the BOLD study was prospectively described elsewhere [15]. All sites aimed at recruiting population-based samples of at least 300 males and 300 females aged $\geqslant 40$ years. Target populations were in well-characterised administrative areas. The current analyses included participants from sites recruited as part of the initial phase of the BOLD study: Australia, Austria, Canada, China, Germany, Iceland, India, Norway, Philippines, Poland, South Africa, Sweden, Turkey, the UK and the USA. Of the 11048 respondents to the survey (individuals with both post-bronchodilator spirometry data and minimal questionnaire data), 10441 (94.5\%) also had acceptable lung function data and were potentially eligible to be included in the analyses. Site-specific sampling strategies and response rates are given in online supplementary table E1. All participants signed informed consent forms, and the study protocol conformed to the Helsinki Declaration and was approved by local ethics committees at all sites.

\section{Data collection}

The BOLD study required cross-sectional surveys of population-based samples. Participants completed a face-to-face interview with trained and certified research assistants. Height, weight, and pre- and postbronchodilator (BD) spirometry were measured. For this report we used questionnaire-derived data on smoking habits, education, occupational exposure, dyspnoea as measured by the mMRC questionnaire [16], attacks of dyspnoea with wheezing, and the presence of the following selected medical conditions: heart 
disease, asthma, emphysema, current chronic bronchitis, COPD, tuberculosis, lung cancer, diabetes, lung surgery and childhood hospitalisations for breathing problems. In non-English-speaking countries, standardised questionnaires were forward and backward translated [15].

The mMRC dyspnoea questions describe five grades of dyspnoea: dyspnoea only with strenuous exercise (grade 0 or normal); dyspnoea when hurrying on the level or up a slight hill (grade 1); dyspnoea when walking at own pace on the level (grade 2); dyspnoea when walking 100 yards or for a few minutes (grade 3); and dyspnoea at rest (grade 4) [16]. Subjects were assigned the highest dyspnoea grade with a positive response. Subjects with inability to walk due to reasons other than dyspnoea were excluded from further analyses, which left 9484 individuals available for the current analyses. The exact wording of all BOLD mMRC questions is included in the online supplementary material.

Spirometry was measured by trained and certified technicians according to American Thoracic Society standards [17] using a portable spirometer (EasyOne; ndd Medizintechnik AG, Zürich, Switzerland). PostBD spirometry was performed $15 \mathrm{~min}$ after $200 \mu \mathrm{g}$ salbutamol had been administered through a spacer. All manoeuvres were reviewed and quality graded at a central pulmonary function reading centre. Predicted and lower limit of normal (LLN) values for the FEV1 and forced vital capacity (FVC) were calculated using the US National Health and Nutrition Examination Survey (NHANES) III prediction equations from healthy Caucasians [18].

For these analyses we defined a restrictive spirometry pattern as a post-BD FVC $<$ LLN and FEV1/FVC $>$ LLN. Chronic airway obstruction was defined as post-BD FEV1/FVC $<$ LLN, whereas spirometric COPD was defined as post-BD FEV1/FVC $<$ LLN and FEV1 \% pred $<$ LLN. Pre-BD obstruction was defined as FEV1/FVC $<$ LLN before administration of salbutamol. A BMI $>30 \mathrm{~kg} \cdot \mathrm{m}^{-2}$ was defined as obesity, while a BMI $<18.5 \mathrm{~kg} \cdot \mathrm{m}^{-2}$ was considered underweight according to World Health Organization guidelines.

\section{The low-risk dyspnoea group}

We defined a subsample in order to investigate the prevalence of dyspnoea when subjects with abnormal spirometry or self-reported dyspnoea-causing conditions were excluded. This low-risk subsample excluded participants with any of the following: self-reported heart disease, asthma, attacks of wheezing with dyspnoea, emphysema, chronic bronchitis, COPD, tuberculosis, lung cancer, pre- or post-BD airway obstruction or a low FVC.

\section{Statistical methods}

We first investigated dyspnoea prevalence in the cohort as a whole and in the dyspnoea low-risk subset as well as the relationship between lung function and dyspnoea. Thereafter, we conducted multivariable ordered logistic regression to identify correlates of mMRC-defined dyspnoea. We used Wald Chi-squared tests to assess statistical significance of individual variables in our models and used reductions in the Wald statistic as a measure of the amount of site-to-site variability that was explainable by other covariates [19]. All analyses ignored sampling weights and instead presented results as unweighted means and regression coefficients.

The outcome variable was the five-level categorical mMRC variable. The regression coefficients from these models represent $\ln$ (odds ratios). Specifically, for an increase of one unit in any given predictor variable, the model assumes that the natural $\log$ odds ratios $(\ln (\mathrm{ORs})$ ) for (mMRC $1-4$ versus mMRC 0$)$, (mMRC $2-4$ versus mMRC $0-1$ ), (mMRC 3-4 versus mMRC $0-2$ ) and (mMRC 4 versus mMRC $0-3$ ) are identical. Thus a positive regression coefficient implies increased severity of dyspnoea with increasing values of the corresponding predictor variable. For a binary indicator of a particular exposure, the regression coefficients therefore represent $\ln (\mathrm{ORs})$ for the exposed group relative to the reference (unexposed) group.

We tested several different models: 1) model 1 estimated the association of dyspnoea with site and sex; 2) model 2 estimated the association of dyspnoea with site, sex, age, smoking status, obesity, underweight, education, occupational exposure to dust, reported doctor-diagnosed or history of heart disease, hypertension, diabetes, tuberculosis, lung surgery and hospitalisation for respiratory disease in childhood; 3 ) model 3 estimated the association of dyspnoea with the factors in model 2, plus post-BD FEV1/FVC below LLN (a dichotomous variable, obstruction or not); 4) model 4 estimated the association of dyspnoea with the factors in model 2, plus post-BD FVC \% pred (a continuous lung function variable); and 5) model 5 estimated the association of dyspnoea with the factors in model 2 plus both lung function parameters from models 3 and 4 .

We also investigated interaction effects between site and sex, but these models are not reported in full. All analyses were performed using Stata 10 for Windows (Stata Corp, College Station, TX, USA). 


\section{TABLE 1 Prevalence and mean of study participant characteristics in 15 countries}

\begin{tabular}{|c|c|}
\hline Age years & $55.5 \pm 11.1$ \\
\hline Male sex & 49 \\
\hline $\mathrm{BMI} \mathrm{kg} \cdot \mathrm{m}^{-2}$ & $26.8 \pm 5.2$ \\
\hline Obesity $\#$ & $2 \overline{2}$ \\
\hline Underweight ${ }^{\text {I }}$ & 2 \\
\hline \multicolumn{2}{|l|}{ Spirometry patterns ${ }^{+}$} \\
\hline Spirometric COPD & 7 \\
\hline Post-BD restriction & 19 \\
\hline Pre-BD obstruction & 17 \\
\hline \multicolumn{2}{|l|}{ Smoking status } \\
\hline Current & 24 \\
\hline Former & 31 \\
\hline Never & 45 \\
\hline \multicolumn{2}{|l|}{ Education } \\
\hline None & 4 \\
\hline Primary/middle school & 27 \\
\hline High school/some college & 48 \\
\hline Four-year college/university & 20 \\
\hline \multicolumn{2}{|l|}{ Self-reported } \\
\hline Hypertension & 28 \\
\hline Heart disease & 11 \\
\hline Diabetes & 7 \\
\hline Tuberculosis & 4 \\
\hline \multicolumn{2}{|l|}{ Self-reported obstructive lung diseases } \\
\hline Current chronic bronchitis & 2 \\
\hline Emphysema & 2 \\
\hline COPD & 1 \\
\hline Asthma & 11 \\
\hline Attacks of wheezing with dyspnoea & 9 \\
\hline
\end{tabular}

Data are presented as mean \pm SD or $\%$. $n=9484$. BMI: body mass index; COPD: chronic obstructive pulmonary disease; BD: bronchodilator. ${ }^{\#}$ : BMI $>30 \mathrm{~kg} \cdot \mathrm{m}^{-2}$. ${ }^{\text {† }}$ : BMI $<18.5 \mathrm{~kg} \cdot \mathrm{m}^{-2}$. ${ }^{+}$: spirometric COPD: post-BD forced expiratory volume in $1 \mathrm{~s}(\mathrm{FEV} 1) /$ forced vital capacity $(\mathrm{FVC})<L L N$ and $F E V 1<L L N$; post-BD restriction: FEV $1 /$ FVC $>$ LLN and FVC $<$ LLN; pre-BD obstruction: FEV1/FVC <LLN. Missing values were as follows: weight, 113 participants; education, 15 participants; self-reported chronic bronchitis, six participants; self-reported emphysema, two participants; pre-BD quality-approved spirometry, 1098 participants; and attacks of wheezing, four participants.

\section{Results}

About one-quarter of participants were obese and $45 \%$ were never-smokers (table 1). A diagnosis of asthma was reported by $11 \%$, but only $1-2 \%$ reported COPD, chronic bronchitis, or emphysema. The prevalence of the four dyspnoea grades by site is shown in figure 1, and exact prevalence and confidence intervals are given in online supplementary table E2. Any dyspnoea (grades 1-4) was reported more frequently by females than males (table 2). These patterns persisted in the low-risk for dyspnoea sample, which included $41 \%$ of the males and $40 \%$ of the females from the entire study population.

Figure 2 shows the unadjusted prevalence of mMRC-defined dyspnoea grades $2-4$ in males and females by FVC \% pred and by FEV1/FVC \% pred, stratified by dyspnoea risk. Lower FVC or lower FEV1/FVC ratio was associated with more dyspnoea in both females and males, but for all levels of lung function there was more dyspnoea in females. The same pattern was found in the low-risk subsample. Figure 3 shows a box plot of FVC \% pred by mMRC grades. Consistent with figure 2, we see a pattern of declining FVC with increasing level of dyspnoea. Although this association was highly significant (one-way ANOVA F=134.8; $\mathrm{p}<0.001$ ), the distributions of FVC nonetheless exhibit considerable overlap across the dyspnoea grades. Online supplementary figure E1 shows a box plot of FEV1\% pred by mMRC grades.

\section{Results of multivariate models}

In ordered logistic regression models, site was a highly significant predictor of dyspnoea, even after adjustment for sociodemographic variables, comorbidities and lung function (table 3). Reductions in the Wald Chi-squared statistic for site can be used as a proxy for the amount of variability associated with siteto-site differences that are explainable by the other variables in the model. So, for instance, the 


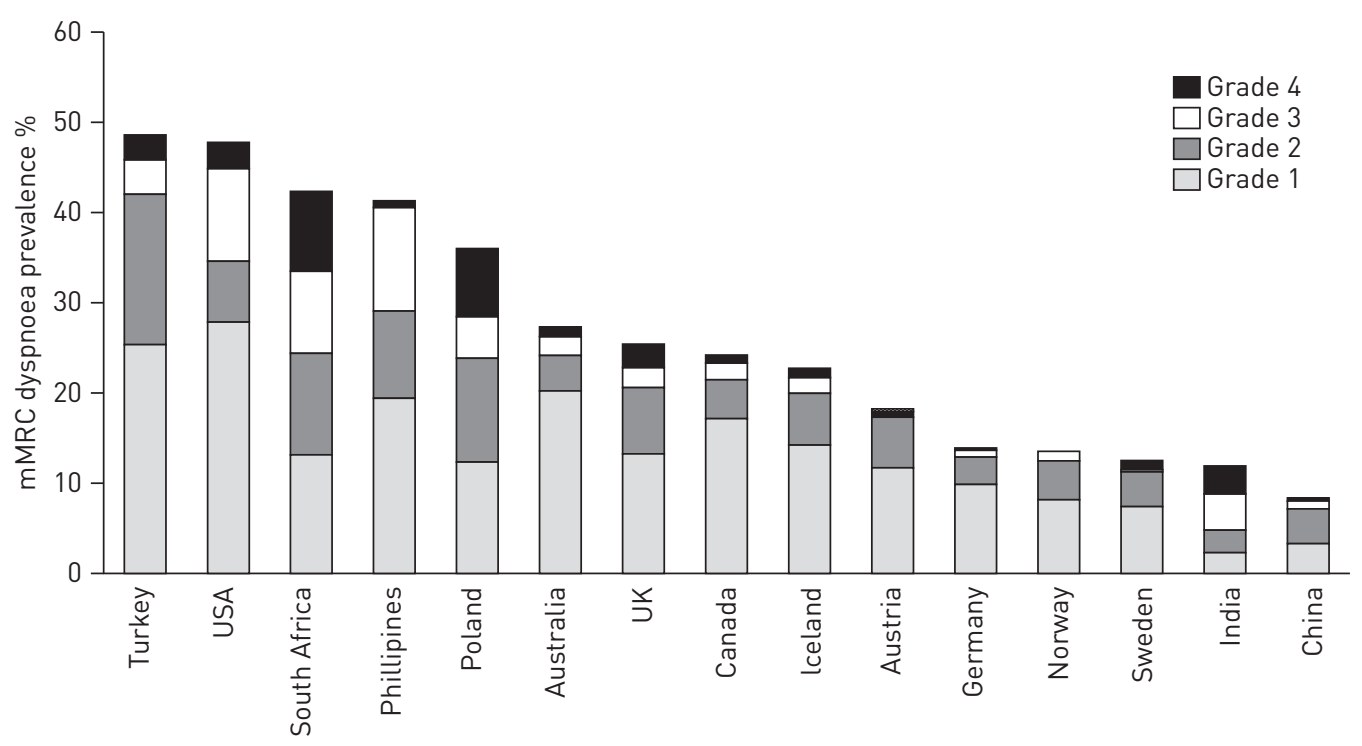

FIGURE 1 Prevalence of modified Medical Research Council (mMRC)-defined dyspnoea grades by site in 15 countries of the Burden of Obstructive Lung Disease study.

sociodemographic and comorbidity variables appear to explain $\sim 45 \%$ of the variability attributable to site, while FVC $\%$ pred explains an additional $6-7 \%$ of site-to-site variability.

In virtually all of the models we examined, female sex; increasing age; less education; both obesity and underweight; both current and past smoking history; occupational dust exposure; reported diagnoses of hypertension, heart disease, diabetes or tuberculosis; prior lung surgery; hospitalisation for breathing problems as a child; and reduced FEV1/FVC and FVC were all associated with increased dyspnoea. The distribution of these risk factors across sites is shown in online supplementary table E3. We also assessed whether the impact of sex on dyspnoea varied by site (data not shown), and observed statistically significant interactions $(\mathrm{p}<0.04)$ for models 3 and 5 . No other interactions were assessed.

Figures 4 and 5 shows the odds ratios for mMRC grade $2-4$ dyspnoea when FVC \% pred and FEV1/FVC \% pred were categorised as in figure 2, and adjusted for the same covariates as in models 2-4. These adjusted analyses reinforce the visual impression from figure 2 .

\section{Discussion}

We observed that dyspnoea exhibited geographical variation beyond that which might be explained by known risk factors such as age, sex, education, smoking habits, comorbidities and spirometry results.

TABLE 2 Prevalence of modified Medical Research Council (mMRC) dyspnoea grades, stratified by health status and sex

All Low risk Males $\quad$ Females

\begin{tabular}{|c|c|c|c|c|c|c|}
\hline & & & & \\
\hline & & & All & Low risk & All & Low risk \\
\hline Subjects $n$ & 9484 & 4329 & 4640 & 2159 & 4844 & 2170 \\
\hline mMRC grade 0 & 73 & 84 & 80 & 89 & 67 & 78 \\
\hline mMRC grade 1 & 14 & 12 & 11 & 8 & 16 & 15 \\
\hline mMRC grade 2 & 7 & 3 & 5 & 2 & 9 & 5 \\
\hline mMRC grade 3 & 4 & 1 & 2 & 0.7 & 5 & 2 \\
\hline mMRC grade 4 & 2 & 0.3 & 2 & 0.1 & 2 & 0.5 \\
\hline
\end{tabular}

Data are presented as \%, unless otherwise stated. The low risk for dyspnoea subgroup of study participants was defined as those without post-pronchodilator (BD) airflow restriction, spirometric chronic obstructive pulmonary disease (COPD) or pre-BD airflow obstruction, or self-reported heart disease, asthma, attacks of wheezing and dyspnoea, emphysema, chronic bronchitis, COPD, tuberculosis or lung cancer. 
a)

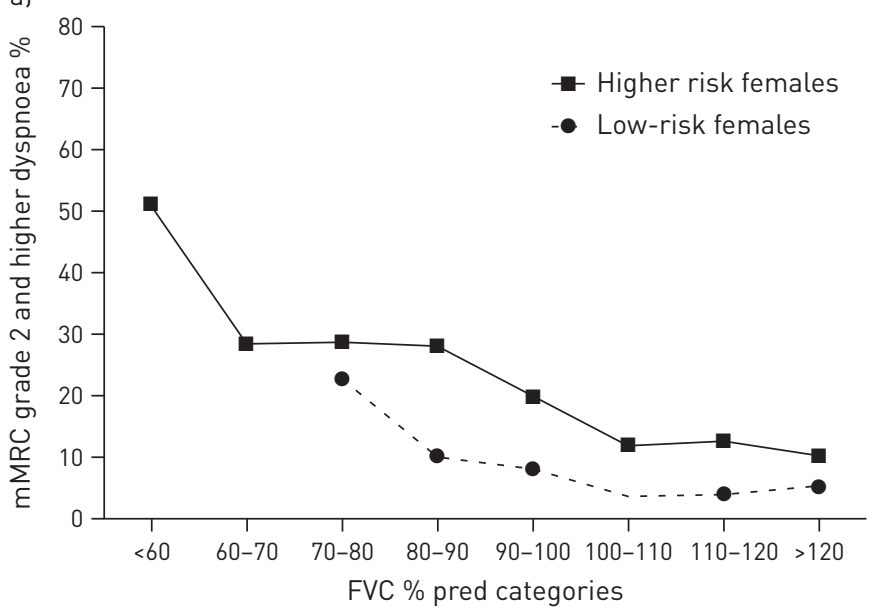

c)

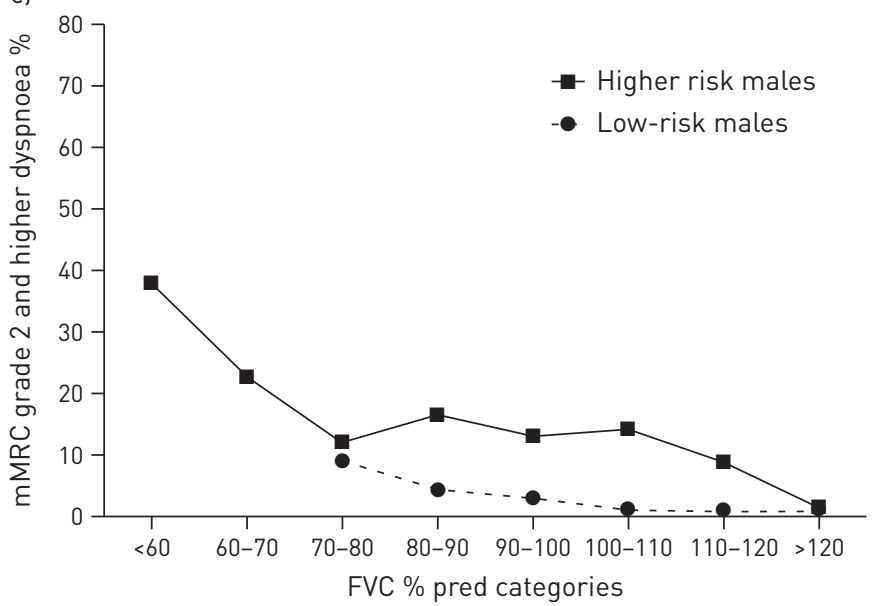

b)

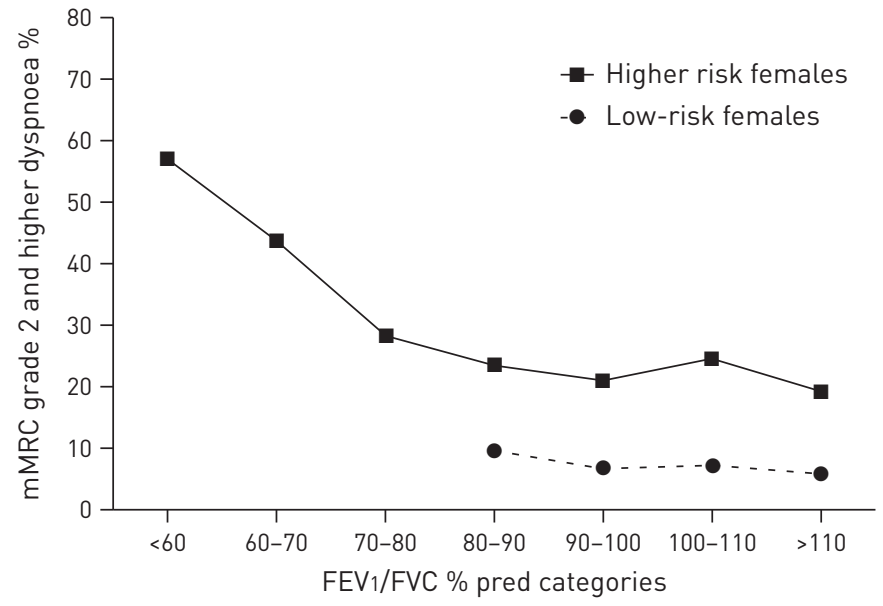

d)

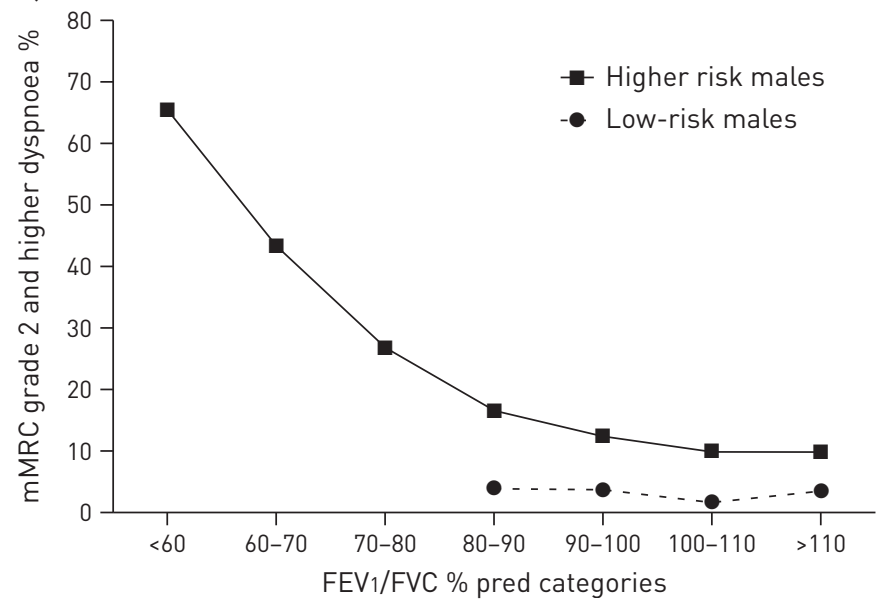

FIGURE 2 Prevalence of modified Medical Research Council (mMRC) grade 2 or higher dyspnoea by a) and c) forced vital capacity (FVC) \% predicted and b) and d) forced expiratory volume in $1 \mathrm{~s}(\mathrm{FEV} 1) / \mathrm{FVC} \%$ pred in participants with a lower risk for dyspnoea, and subjects with higher risk for dyspnoea, stratified by sex. See table 2 footnote for the definition of the low-risk group and table 2 for number of participants.

However, despite comprehensive information, only 13\% of dyspnoea variance was explained in these multivariate analyses.

Both in bivariate and multivariate analyses, we observed a much higher risk of dyspnoea when FVC \% pred and $\mathrm{FEV} 1 / \mathrm{FVC} \%$ pred fell below $60 \%$ and $70 \%$, respectively. In addition, dyspnoea was reported in nearly one in six study participants in the low-risk group for dyspnoea. A change of lifestyle and issues regarding how to measure dyspnoea across cultural and linguistic borders might explain some dyspnoea variance, but more research is clearly needed on the heterogeneity of dyspnoea.

The heterogeneity of dyspnoea across sites remained highly significant in all our multivariate models, but adjustment for an increasing number of covariates clearly reduced this variation. The European Respiratory Health Survey (ECRHS) showed site variation in asthma-related dyspnoea symptoms [10], but concluded that, in multivariate analyses, there was no significant site heterogeneity [20]. The PLATINO study found significant effects of sex, age, education, FEV1, comorbid diseases, wheeze, cough, phlegm and healthrelated quality of life on MRC-defined dyspnoea [11]. The current results from the BOLD study confirm that most of these predictors were also present in population-based samples worldwide. As in previous reports, the odds of more dyspnoea in females were about twice those of males. However, despite a large number of centres, the ECRHS emphasised asthmatic symptoms in young adults and did not include Asian, South-American or African countries. The PLATINO study consisted of five cities in one subcontinent. The BOLD study, with its greater global spread, may have greater ability to show true geographical variation.

We observed an accelerated increase in prevalence of dyspnoea with decreasing FVC and FEV1/FVC. JAKEWAYs et al. [7] observed similar patterns in a single site study, but did not adjust for potential 


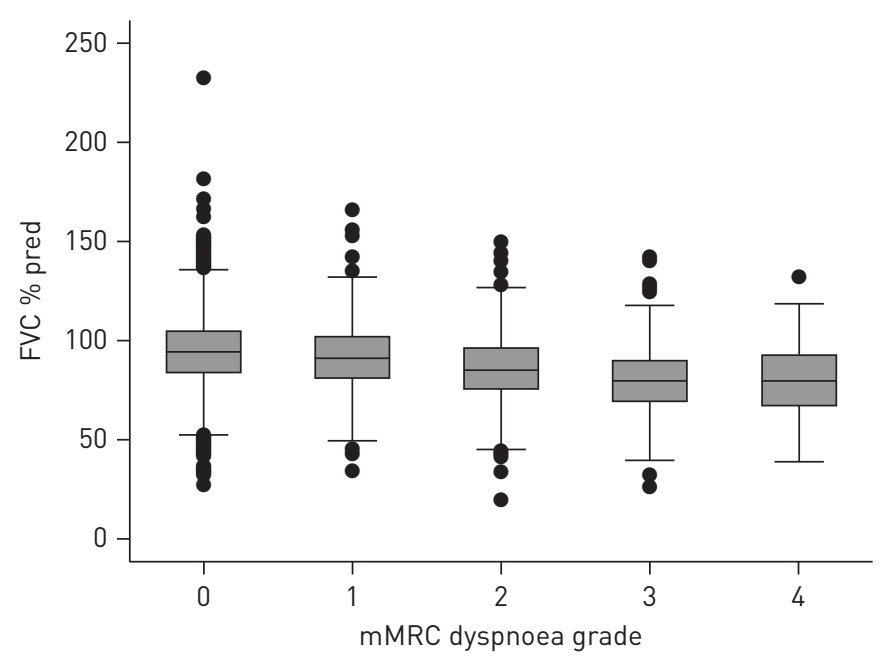

FIGURE 3 Box plot of forced vital capacity (FVC) \% predicted by modified Medical Research Council (mMRC) dyspnoea. The box represents the interquartile range (IQR), the line within the box is the median value and the whiskers show values within $1.5 \mathrm{IQR}$ of the adjacent quartile. Outliers are plotted.

confounders. The visual inspection of our data, although not formally tested, also appeared consistent with findings in studies where activity-related dyspnoea was elicited during cardiopulmonary exercise testing [21].

The association between FVC and dyspnoea supports recent findings by BURNEY and HoOPER [22] who observed in data also from the BOLD Study that an association between FEV1 and mortality disappeared after adjusting for FVC in subjects without known chronic respiratory diseases or symptoms. In patients with COPD or asthma, a low FEV1 is an index of the severity of airway obstruction, while a low FVC is often

TABLE 3 Odds ratios (95\% confidence intervals) for variables predicting a higher category of dyspnoea using ordered logistic regression models

\begin{tabular}{|c|c|c|c|c|c|}
\hline & Model 1 & Model $2^{\#}$ & Model $3^{\#}$ & Model $4^{\#}$ & Model $5^{\#}$ \\
\hline Participants in model $\mathbf{n}$ & 9484 & 9334 & 9334 & 9334 & 9334 \\
\hline $\mathbf{R}^{2}$ pseudo $\%$ & 5.9 & 11.3 & 12.1 & 12.6 & 13.4 \\
\hline $\begin{array}{l}\text { Site, overall effect, Wald } \\
\text { Chi-squared }\end{array}$ & $748, p<0.001$ & 414, $p<0.001$ & 416, $p<0.001$ & $365, p<0.001$ & $355, p<0.001$ \\
\hline Female & $1.78(1.62-1.96)$ & $2.13(1.91-2.37)$ & $2.11(1.89-2.35)$ & $2.19(1.96-2.44)$ & $2.16(1.94-2.42)$ \\
\hline Age (10-year increase) & & $1.22(1.16-1.28)$ & $1.17(1.11-1.23)$ & $1.24(1.18-1.31)$ & $1.19(1.13-1.25)$ \\
\hline High school education & & $0.74(0.64-0.84)$ & $0.75(0.65-0.86)$ & $0.75(0.65-0.86)$ & $0.75(0.66-0.87)$ \\
\hline $\begin{array}{l}\text { College or university } \\
\text { education }\end{array}$ & & $0.57(0.50-0.67)$ & $0.59(0.51-0.68)$ & $0.59(0.50-0.68)$ & $0.60(0.52-0.70)$ \\
\hline Current smoker & & $1.99(1.75-2.27)$ & $1.75(1.53-1.99)$ & $1.94(1.70-2.22)$ & $1.71(1.49-1.96)$ \\
\hline Ex-smoker & & $1.36(1.20-1.54)$ & $1.27(1.12-1.44)$ & $1.37(1.21-1.55)$ & $1.28(1.12-1.45)$ \\
\hline Dust exposure at work & & $1.44(1.29-1.61)$ & $1.42(1.27-1.58)$ & $1.46(1.31-1.63)$ & $1.44(1.29-1.61)$ \\
\hline Lung surgery & & $4.05(2.18-7.53)$ & $3.47(1.81-6.63)$ & $3.40(1.87-6.18)$ & $2.94(1.58-5.48)$ \\
\hline $\begin{array}{l}\text { Childhood hospitalisation } \\
\text { for breathing problems }\end{array}$ & & $1.54(1.17-2.02)$ & $1.45(1.11-1.90)$ & $1.49(1.14-1.96)$ & $1.40(1.07-1.84)$ \\
\hline FEV $_{1} /$ FVC $<$ LLN & & & $2.33(2.02-2.68)$ & & $2.29(1.98-2.64)$ \\
\hline $\begin{array}{l}\text { FVC } \% \text { pred per } 10 \% \\
\text { increase }\end{array}$ & & & & $0.77(0.74-0.80)$ & $0.78(0.75-0.81)$ \\
\hline
\end{tabular}

FEV1: forced expiratory volume in $1 \mathrm{~s}$; FVC: forced vital capacity; LLN: lower limit of normal. " : missing values for models 2-4: weight, 113 subjects; education, 15 subjects; lung surgery, one subject; and childhood breathing problems, 21 subjects. FEV1/FVC and FVC \% predicted was measured post-bronchodilator. 


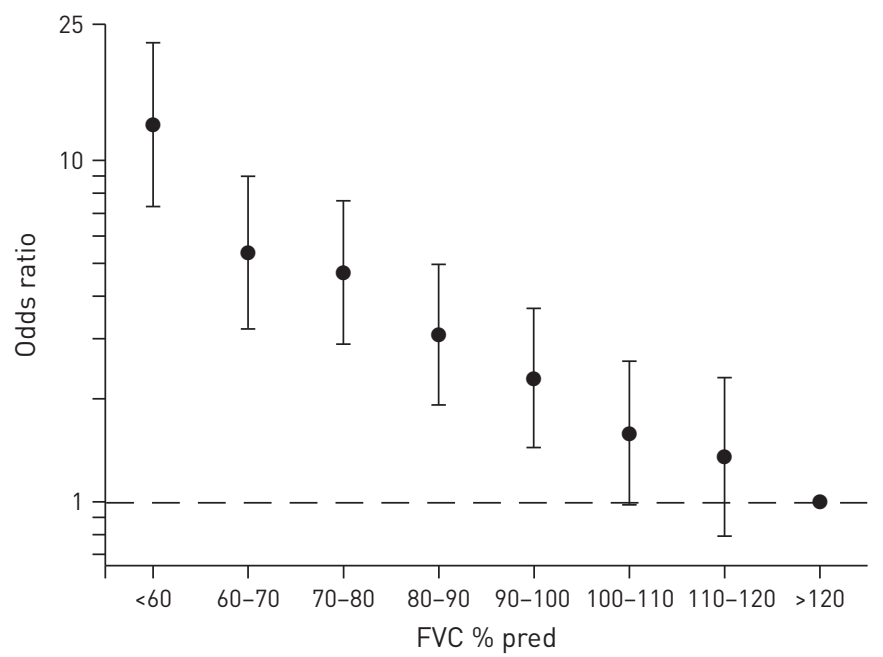

FIGURE 4 Odds ratio (logistic regression) for modified Medical Research Council (mMRC) grade 2 and higher dyspnoea at different levels of forced vital capacity (FVC) \% predicted. Adjusted for all covariates listed in table 3 except for lung function variables. Error bars represent $95 \%$ confidence interval. $n=9334$.

due to hyperinflation (air trapping) or obesity. Although closely related, these two mechanisms of pathology are not identical. It might be that the inclusion of FVC when assessing risk and symptoms of COPD could improve the performance of the suggested new classification of COPD [23]. A low FVC may also be associated with poverty [24] and, if this is the case, the origins may be developmental i.e. in utero.

Although we have found strong associations between dyspnoea and several covariates, the coefficient of determination, or $\mathrm{R}^{2}$, of our multivariate models indicated that we only were able to explain $13 \%$ of dyspnoea variance. Several factors might account for this phenomenon. First, some dyspnoea probably represents a truely unexplainable variation. Secondly, several factors were not measured, such as the individual level of stimuli sensitivity, level of physical activity, verified comorbidities, cardiovascular function and external variables, such as air pollution and altitude. However, we did include information regarding key disease groups and lung function parameters. Thirdly, the chosen measurement method for dyspnoea (the mMRC) has some limitations. The mMRC measures the impact domain of activity-related dyspnoea, but breathlessness with activity is not necessarily perceived as discomforting, and does not necessarily represent dyspnoea [25]. Furthermore, the definition somehow assumes that this physical activity is a part of everyday life. However, both industrialised and developing countries are affected by a

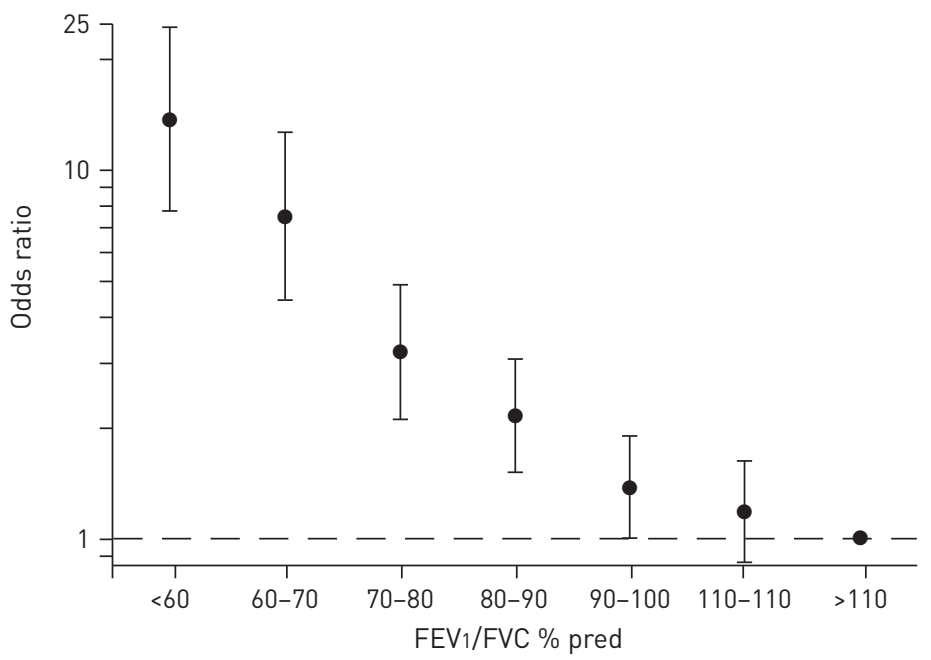

FIGURE 5 Odds ratio (logistic regression) for modified Medical Research Council (mMRC) grade 2 and higher dyspnoea at different levels of forced expiratory volume in $1 \mathrm{~s}$ (FEV1)/forced vital capacity (FVC) \% predicted (not absolute). Adjusted for all covariates listed in table 3 except lung function variables. Error bars represent $95 \%$ confidence interval. $\mathrm{n}=9334$. 
global epidemic of inactivity and obesity [26]. If physical deconditioning is not to be regarded a disease, then one might hypothesise a baseline level of exercise-related breathlessness, explaining some of the $16 \%$ dyspnoea observed in the a priori low-risk group. Fourthly, we do not know whether the observed geographical variation represented site-to-site variation or variation by country. However, the BOLD study had a strong quality control programme and used a forward and backward translation process for the questionnaires used in non-English-speaking countries. Despite our careful attention to quality control, it is still possible that site differences may be the result of language and cultural differences in the understanding, recognition and expression of symptoms.

Two major strengths of the BOLD study are the population-based samples and the application of uniform, standardised methods with careful quality control. By using ordered logistic regression, we have been able to include all information in the mMRC dyspnoea scale instead of choosing some more or less arbitrary cut-off point. This approach to statistical modelling might be challenging. Formal statistical testing indicated that these data do not meet the proportional odds assumption, although the significance of this test may in part reflect our very large sample size. Nonetheless, we feel it is still a useful analysis that attempts to reflect the multilevel nature of the mMRC dyspnoea score.

We observed a large number of participants with a restrictive spirometry pattern. This might reflect difficulties with reaching the true residual volume during a forced expiratory manoeuvre despite very careful attention to training and certification of technicians. However, it might also reflect that we used a common reference equation for lung function variables rather than local reference values. However, it has been shown that it is not necessary to adjust the FEV1/FVC ratio with regards to ethnicity [27], and that such adjustments of the FVC \% pred might obscure associations between this variable and markers of a poor prognosis [28]. Thus, our position has been that if we applied local reference equations or adjusted for ethnicity in global reference equations, we could risk obscuring associations between FVC and dyspnoea.

One possible interpretation of our results might be that dyspnoea is of limited usefulness as a marker of impaired health, as known risk factors and diseases explained only $13 \%$ of variance. Conversely, dyspnoea is a strong predictor of hard end-points $[1,29,30]$, and the minor impact of adding spirometry information to our models underscores the inclusion of symptoms in clinical guidelines in respiratory medicine alongside pulmonary function data [23].

In conclusion, we have found significant variation in dyspnoea prevalence across 15 countries of the BOLD study. Consequently, the cross-cultural validity of research based on dyspnoea as an outcome needs to be reaffirmed. Furthermore, we found a marked increase in dyspnoea prevalence as FVC fell below $60 \%$ pred. We also observed considerable dyspnoea reporting in participants without obvious causes for breathlessness. The interpretation of exercise-related dyspnoea should not be static, and dyspnoea in this subgroup might be attributed to causes other than disease, for instance, a modern, sedentary lifestyle. Finally, the key finding was that in a large epidemiological study with comprehensive participant-derived information and high-quality pulmonary function data, only a minor fraction of dyspnoea variation could be explained.

\section{Acknowledgements}

This paper is dedicated to the memory of Michael Lebowitz, a superb pulmonary epidemiologist from Tucson, AZ, USA, who collaborated with investigators in many countries.

Additional local support for BOLD sites was provided by the following. Boehringer Ingelheim China (GuangZhou, China); Turkish Thoracic Society, Boehringer-Ingelheim and Pfizer (Adana, Turkey); Altana, Astra-Zeneca, BoehringerIngelheim, GlaxoSmithKline, Merck Sharpe \& Dohme, Novartis, Salzburger Gebietskrankenkasse and Salzburg Local Government (Salzburg, Austria); Research for International Tobacco Control, the International Development Research Centre, the South African Medical Research Council, the South African Thoracic Society GlaxoSmithKline Pulmonary Research Fellowship and the University of Cape Town Lung Institute (Cape Town, South Africa); Landspítali-University Hospital-Scientific Fund, GlaxoSmithKline Iceland and AstraZeneca Iceland (Reykjavik, Iceland); GlaxoSmithKline Pharmaceuticals, Polpharma, Ivax Pharma Poland, AstraZeneca Pharma Poland, ZF Altana Pharma, Pliva Kraków, Adamed, Novartis Poland, Linde Gaz Polska, Lek Polska, Tarchomińskie Zakłady Farmaceutyczne Polfa, Starostwo Proszowice, Skanska, Zasada, Agencja Mienia Wojskowego w Krakowie, Telekomunikacja Polska, Biernacki, Biogran, Amplus Bucki, Skrzydlewski, Sotwin and Agroplon (Krakow, Poland); Boehringer-Ingelheim and Pfizer Germany (Hannover, Germany); the Norwegian Ministry of Health's Foundation for Clinical Research and Haukeland University Hospital's Medical Research Foundation for Thoracic Medicine (Bergen, Norway); AstraZeneca, Boehringer-Ingelheim, Pfizer and GlaxoSmithKline (Vancouver, Canada); Marty Driesler Cancer Project (Lexington, KY, USA); Altana, Boehringer Ingelheim (Phil), GlaxoSmithKline, Pfizer, Philippine College of Chest Physicians, Philippine College of Physicians and United Laboratories (Phil) (Manila, Philippines); Air Liquide Healthcare P/L, AstraZeneca P/L, Boehringer Ingelheim P/L, GlaxoSmithKline Australia P/L, Pfizer Australia P/L (Sydney, Australia); Dept of Health Policy Research Programme, Clement Clarke International (London, UK); Swedish Heart and Lung Foundation, The Swedish Association against Heart and Lung Diseases, GlaxoSmithKline (Uppsala, Sweden); and Foundation for Environmental Medicine, Kasturba Hospital, Volkart Foundation (Mumbai, India). 
The BOLD Collaboration is as follows. A. Sonia Buist, William Vollmer, Suzanne Gillespie, MaryAnn McBurnie (BOLD Co-ordinating Centre, Kaiser Permanente, Portland, OR, USA); Peter G.J. Burney, Anamika Jithoo, Louisa Gnatiuc, Bernet Kato, Sonia Coton, Hadia Azhar (BOLD Co-ordinating Centre, Imperial College London, London, UK); NanShan Zhong (PI), Shengming Liu, Jiachun Lu, Pixin Ran, Dali Wang, Jingping Zheng, Yumin Zhou (Guangzhou Institute of Respiratory Diseases, Guangzhou Medical College, Guangzhou, China); Ali Kocabaş (PI), Attila Hancioglu, Ismail Hanta, Sedat Kuleci, Ahmet Sinan Turkyilmaz, Sema Umut, Turgay Unalan (Cukurova University School of Medicine, Dept of Chest Diseases, Adana, Turkey); Michael Studnicka (PI), Torkil Dawes, Bernd Lamprecht, Lea Schirhofer (Paracelsus Medical University, Dept of Pulmonary Medicine, Salzburg, Austria); Eric Bateman (PI), Anamika Jithoo (PI), Desiree Adams, Edward Barnes, Jasper Freeman, Anton Hayes, Sipho Hlengwa, Christine Johannisen, Mariana Koopman, Innocentia Louw, Ina Ludick, Alta Olckers, Johanna Ryck, Janita Storbeck (University of Cape Town Lung Institute, Cape Town, South Africa); Thorarinn Gislason (PI), Bryndis Benedikdtsdottir, Kristin Jörundsdottir, Lovisa Gudmundsdottir, Sigrun Gudmundsdottir, Gunnar Gundmundsson (Landspitali University Hospital, Dept of Allergy, Respiratory Medicine and Sleep, Reykjavik, Iceland); Ewa Nizankowska-Mogilnicka (PI), Jakub Frey, Rafal Harat, Filip Mejza, Pawel Nastalek, Andrzej Pajak, Wojciech Skucha, Andrzej Szczeklik, Magda Twardowska (Division of Pulmonary Diseases, Dept of Medicine, Jagiellonian University School of Medicine, Cracow, Poland); Tobias Welte (PI), Isabelle Bodemann, Henning Geldmacher, Alexandra Schweda-Linow (Hannover Medical School, Hannover, Germany); Amund Gulsvik (PI), Tina Endresen, Lene Svendsen (Dept of Thoracic Medicine, Institute of Medicine, University of Bergen, Bergen, Norway); Wan C. Tan (PI), Wen Wang (iCapture Center for Cardiovascular and Pulmonary Research, University of British Columbia, Vancouver, BC, Canada); David M. Mannino (PI), John Cain, Rebecca Copeland, Dana Hazen, Jennifer Methvin (University of Kentucky, Lexington, KY, USA); Renato B. Dantes (PI), Lourdes Amarillo, Lakan U. Berratio, Lenora C. Fernandez, Norberto A. Francisco, Gerard S. Garcia, Teresita S. de Guia, Luisito F. Idolor, Sullian S. Naval, Thessa Reyes, Camilo C. Roa Jr, Ma. Flordeliza Sanchez, Leander P. Simpao (Philippine College of Chest Physicians, Manila, Philippines); Christine Jenkins (PI), Guy Marks (PI), Tessa Bird, Paola Espinel, Kate Hardaker, Brett Toelle (Woolcock Institute of Medical Research, Sydney, Australia); Peter G.J. Burney (PI), Caron Amor, James Potts, Michael Tumilty, Fiona McLean (National Heart and Lung Institute, Imperial College, London, UK); E.F.M. Wouters, G.J. Wesseling (Maastricht University Medical Center, Maastricht, the Netherlands); Christer Janson (PI), Inga Sif Olafsdottir, Katarina Nisser, Ulrike Spetz-Nyström, Gunilla Hägg and Gun-Marie Lund (Dept of Medical Sciences, Respiratory Medicine and Allergology, Uppsala University, Sweden); and Rohini Chowgule (PI) Vasant Shetye, Jonelle Raphael, Rosel Almeda, Mahesh Tawde, Rafiq Tadvi, Sunil Katkar, Milind Kadam, Rupesh Dhanawade, Umesh Ghurup (Indian Institute of Environmental Medicine, Mumbai, India).

In the first phase of the study, R.O. Crapo and R.L. Jensen (LDS Hospital, Salt Lake City, UT, USA) were responsible for quality assurance of lung function; they and Paul Enright (The University of Arizona, Tucson, AZ, USA) and Georg Harnoncourt (ndd Medizintechnik AG, Zurich, Switzerland) assisted with training lung function technicians.

\section{References}

1 Frostad A, Soyseth V, Andersen A, et al. Respiratory symptoms as predictors of all-cause mortality in an urban community: a 30-year follow-up. J Intern Med 2006; 259: 520-529.

2 The World Health Organization (WHO). The global burden of disease. 2004 update. Geneva, WHO Press, 2008 www.who.int/healthinfo/global_burden_disease/2004_report_update/en/. Date last accessed: October 4, 2011.

3 Bestall JC, Paul EA, Garrod R, et al. Usefulness of the Medical Research Council (MRC) dyspnoea scale as a measure of disability in patients with chronic obstructive pulmonary disease. Thorax 1999; 54: 581-586.

4 Steer J, Norman EM, Afolabi OA, et al. Dyspnoea severity and pneumonia as predictors of in-hospital mortality and early readmission in acute exacerbations of COPD. Thorax 2012; 67: 117-121.

5 Lindström M, Kotaniemi J, Jönsson E, et al. Smoking, respiratory symptoms, and diseases: a comparative study between northern Sweden and northern Finland: report from the FinEsS study. Chest 2001; 119: 852-861.

6 Eagan TM, Bakke PS, Eide GE, et al. Incidence of asthma and respiratory symptoms by sex, age and smoking in a community study. Eur Respir J 2002; 19: 599-605.

7 Jakeways N, McKeever T, Lewis SA, et al. Relationship between FEV1 reduction and respiratory symptoms in the general population. Eur Respir J 2003; 21: 658-663.

8 Enright PL, Kronmal RA, Higgins MW, et al. Prevalence and correlates of respiratory symptoms and disease in the elderly. Cardiovascular Health Study. Chest 1994; 106: 827-834.

9 Hardie JA, Vollmer WM, Buist AS, et al. Respiratory symptoms and obstructive pulmonary disease in a population aged over 70 years. Respir Med 2005; 99: 186-195.

10 Variations in the prevalence of respiratory symptoms, self-reported asthma attacks, and use of asthma medication in the European Community Respiratory Health Survey (ECRHS). Eur Respir J 1996; 9: 687-695.

11 Lopez Varela MV, Montes de Oca M, Halbert RJ, et al. Sex-related differences in COPD in five Latin American cities: the PLATINO study. Eur Respir J 2010; 36: 1034-1041.

12 Gulsvik A. Prevalence of respiratory symptoms in the city of Oslo. Scand J Respir Dis 1979; 60: 275-285.

13 Hammond EC. Some preliminary findings on physical complaints from a prospective study of 1,064,004 men and women. Am J Public Health Nations Health 1964; 54: 11-23.

14 Menezes AM, Perez-Padilla R, Jardim JR, et al. Chronic obstructive pulmonary disease in five Latin American cities (the PLATINO study): a prevalence study. Lancet 2005; 366: 1875-1881.

15 Buist AS, Vollmer WM, Sullivan SD, et al. The Burden of Obstructive Lung Disease Initiative (BOLD): rationale and design. COPD 2005; 2: 277-283.

16 Brooks SM. Task group on surveillance for respiratory hazards in the occupational setting. ATS News 1982; 8: 12-16.

17 Standardization of Spirometry, 1994 Update. American Thoracic Society. Am J Respir Crit Care Med 1995; 152: $1107-1136$.

18 Hankinson JL, Odencrantz JR, Fedan KB. Spirometric reference values from a sample of the general U.S. population. Am J Respir Crit Care Med 1999; 159: 179-187.

19 Hardin JW, Hilbe JM. Generalized Linear Models and Extensions. 2nd Edn. College Station, Stata Press, 2007.

20 Sunyer J, Basagana X, Roca J, et al. Relations between respiratory symptoms and spirometric values in young adults: the European community respiratory health study. Respir Med 2004; 98: 1025-1033. 
21 O’Donnell DE, Ora J, Webb KA, et al. Mechanisms of activity-related dyspnea in pulmonary diseases. Respir Physiol Neurobiol 2009; 167: 116-132.

22 Burney PG, Hooper R. Forced vital capacity, airway obstruction and survival in a general population sample from the USA. Thorax 2011; 66: 49-54.

23 Global Initiative for Chronic Obstructive Lung Disease (GOLD) 2013. The Global Stategy for the Diagnosis, Management and Prevention of COPD. Available from: http://www.goldcopd.org. Date last accessed: May 21, 2013. Date last updated: January 2014.

24 Duong M, Islam S, Rangarajan S, et al. Global differences in lung function by region (PURE): an international, community-based prospective study. Lancet Respir Med 2013; 1: 599-609.

25 Parshall MB, Schwartzstein RM, Adams L, et al. An official American Thoracic Society statement: update on the mechanisms, assessment, and management of dyspnea. Am J Respir Crit Care Med 2012; 185: 435-452.

26 Swinburn BA, Sacks G, Hall KD, et al. The global obesity pandemic: shaped by global drivers and local environments. Lancet 2011; 378: 804-814.

27 Quanjer PH, Stanojevic S, Cole TJ, et al. Multi-ethnic reference values for spirometry for the 3-95-yr age range: the global lung function 2012 equations. Eur Respir J 2012; 40: 1324-1343.

28 Burney PG, Hooper RL. The use of ethnically specific norms for ventilatory function in African-American and white populations. Int J Epidemiol 2012; 41: 782-790.

29 Abidov A, Rozanski A, Hachamovitch R, et al. Prognostic significance of dyspnea in patients referred for cardiac stress testing. N Engl J Med 2005; 353: 1889-1898.

30 Nishimura K, Izumi T, Tsukino M, et al. Dyspnea is a better predictor of 5-year survival than airway obstruction in patients with COPD. Chest 2002; 121: 1434-1440. 